\title{
Fatigue and quality of life in breast cancer survivors: a comparative study
}

\author{
Fadiga e qualidade de vida em pacientes sobreviventes \\ de câncer de mama: um estudo comparativo
}

Original Article

Breast neoplasms

Survivors

Fatigue

Quality of life

Palavras-chave

Neoplasias da mama

Sobreviventes

Fadiga

Qualidade de vida

\section{Abstract}

PURPOSE: To assess fatigue and quality of life in disease-free breast cancer survivors in relation to a sample of age-matched women with no cancer history and to explore the relationship between fatigue and quality of life. METHODS: A cross-sectional study was conducted in a sample of 202 consecutive disease-free Brazilian breast cancer survivors, all of whom had completed treatment, treated at 2 large hospitals. The patients were compared to age-matched women with no cancer history attending a primary health care center. The Piper Fatigue Scale-Revised and the World Health Organization Quality of Life Instrument (WHOQOL-BREF) were used to measure the fatigue and quality of life, respectively. Socio-demographic and clinical variables were also obtained. The $\chi^{2}$ test, generalized linear model, and Spearman correlation coefficient were used for statistical purposes. The adopted level of significance was 5\%. RESULTS: Breast cancer survivors experienced significantly greater total and subscale fatigue scores than comparison group (all p-values<0.05). In addition, survivors reported a poorer quality of life in physical ( $p=0.002$ ), psychological ( $p=0.03$ ), and social relationships ( $p=0.03$ ) domains than comparison group. No difference was found for the environmental domain ( $p=0.08$ ) for both groups. For survivors of breast cancer and for comparison group, the total and subscale fatigue scores were related to lower quality of life (all p-values $<0.01$ ). CONCLUSION: The findings of this study highlight the importance of assessing fatigue and quality of life in breast cancer survivors.

\section{Resumo}

OBJETIVO: Avaliar a fadiga e a qualidade de vida de sobreviventes de câncer de mama, livres da doença, em relação a uma amostra de mulheres da mesma idade, sem histórico de câncer, e explorar a relação entre fadiga e qualidade de vida. MÉTODOS: Estudo transversal realizado com uma amostra consecutiva de 202 pacientes brasileiras, sobreviventes de câncer de mama e livres da doença, que haviam completado o tratamento em 2 grandes hospitais. As pacientes foram comparadas com mulheres da mesma idade, sem história de câncer, acompanhadas em uma Unidade Básica de Saúde. A Escala de Fadiga de Piper-Revisada e o World Health Organization Quality of Life Instrument (WHOQOL-BREF) foram usados para avaliar a fadiga e a qualidade de vida, respectivamente. Dados sociodemográficos e clínicos também foram obtidos. $\bigcirc$ teste do $\chi^{2}$, modelo linear generalizado e coeficiente de correlação de Spearman foram utilizados para fins estatísticos. Foi adotado o nível de significância de $5 \%$. RESULTADOS: As sobreviventes de câncer de mama apresentaram significativamente maiores escores de fadiga total e das subescalas do que o grupo controle (todos os valores de $\mathrm{p}<0,05$ ). Além disso, as sobreviventes relataram pior qualidade de vida nos domínios físico $(p=0,002)$, psicológico $(p=0,03)$ e relações sociais $(p=0,03)$ do que o grupo controle. Nenhuma diferença foi encontrada para o domínio ambiental $(p=0,08)$ entre os 2 grupos. Para as sobreviventes de câncer de mama e para o grupo controle, os escores de fadiga total e das subescalas estavam relacionados à baixa qualidade de vida (todos os valores de p<0,01). CONCLUSÃO: Os resultados deste estudo destacam a importância de avaliar a fadiga e a qualidade de vida em pacientes sobreviventes de câncer de mama.
Correspondence

Ana Claudia Garabeli Cavalli Kluthcovsky Universidade Estadual de Ponta Grossa, Departamento de Medicina Avenida General Carlos Cavalcanti, 4.748 Zip code: $84030-900$ Ponta Grossa (PR), Brazil

Received $11 / 26 / 2014$

Accepted with modifications $01 / 26 / 2015$
Hospital Erasto Gaertner, Hospital de Clínicas da Universidade Federal do Paraná - UFPR • Unidade Municipal de Saúde Ouvidor Pardinho - Curitiba (PR), Brazil.

'Department of Medicine, Universidade Estadual de Ponta Grossa - UEPG - Ponta Grossa (PR), Brazil.

2Department of Tocogynecology, Universidade Federal do Paraná - UFPR - Curitiba (PR), Brazil.

Conflict of interests: none. 


\section{Introduction}

Breast cancer rates are generally increasing ${ }^{1}$, and it is estimated that more than 1.68 million women were diagnosed with breast cancer in 2012 worldwide 2 . In Brazil, an estimative of 56.1 cases of breast cancer per 100,000 women are expected in $2014^{3}$.

In the United States, it was estimated that there were approximately 14.5 million cancer survivors in January 2014, and the most common cancer represented sites include female breast $(22 \%)^{4}$. Given that the number of long-term survivors of cancer has increased because of advances in early detection and treatment $t^{5}$, understanding how long-term side effects and treatment-related symptoms impact the quality of life in cancer survivors, it is critical to reduce the burden of cancer and enhance treatment.

Cancer survivors may suffer from late effects after completing cancer therapy, such as fatigue ${ }^{6}$. Fatigue has been documented as one of the most distressing symptoms reported by breast cancer survivors ${ }^{7}$. Despite the high prevalence of fatigue in cancer patients and the fact that the majority of these patients report fatigue as a major obstacle in daily activities and quality of life, this symptom is seldom assessed and treated ${ }^{8}$.

Many studies suggest that fatigue is a common problem experienced by female survivors of breast can$\operatorname{cer}^{6,9-15}$. Moreover, previous studies have confirmed that breast cancer survivors with increased fatigue rated their quality of life at a lower level ${ }^{12-14,16}$. On the other hand, assessing fatigue in cancer survivors is a challenge since fatigue is also a common complaint with some level of fatigue reported by the general population ${ }^{17,18}$.

The comparison of fatigue between breast cancer survivors and women with no cancer history can serve as a useful approach to determine the magnitude of the problem for cancer survivors ${ }^{19}$. Numerous previous studies ${ }^{9,10,15,19-22}$ have demonstrated increased levels of fatigue in post-treatment breast cancer survivors compared with the control group (e.g. healthy women, women without a history of cancer and/or with a benign breast disease). Contrary to these studies, no differences in fatigue were observed in post-treatment breast cancer women compared with controls ${ }^{23,24}$.

Regarding the quality of life, previous studies have reported conflicting results. Researchers have reported that breast cancer survivors displayed poorer quality of life than control groups $s^{15,21,25-27}$, whereas other authors have not ${ }^{23,24,26,28,29}$.

Studies on fatigue and quality of life in female survivors of breast cancer were conducted in developed countries, which differ culturally and economically from developing countries, such as Brazil. Questions remain regarding whether breast cancer survivors display increased levels of fatigue and poorer quality of life than people without cancer in this country. Comparisons between these groups of women can prove a more clear understanding of the differences in fatigue and quality of life. For these reasons, the aims of this study were to evaluate fatigue and quality of life in disease-free Brazilian breast cancer survivors who completed treatment compared with age-matched women with no cancer history receiving treatment at a primary health care center and to explore the possible association between fatigue and quality of life.

\section{Methods}

\section{Participants and procedures}

The current report was derived from a doctoral project about fatigue and quality of life in Brazilian breast cancer survivors, compared with two age-matched control groups (healthy women and women with no cancer history). Fatigue in breast cancer survivors ${ }^{30}$ and quality of life in breast cancer survivors compared to healthy women ${ }^{31}$ were previously described. This cross-sectional study involves breast cancer survivors and a comparison group of age-matched women with no cancer history.

Female breast cancer survivors were selected among patients who had undergone routine follow-up and consecutively received treatment at outpatient facilities in Erasto Gaertner Hospital (a specialized cancer hospital) and Hospital de Clínicas at Universidade Federal do Paraná (a tertiary care teaching hospital). To be eligible for the study, these women had to be patients with primary breast cancer receiving a diagnosis more than one year before data collection and treatment at one of the two hospitals. In addition, these women should be 18 years of age or older and possess cognitive function and communication abilities. Women with evidence of metastatic or recurrent cancer at the time of the study or those with a history of other types of cancer were excluded.

Prior to data collection, medical records were reviewed to select potentially eligible patients. Among 217 women, 5 refused to participate, and 6 could not be contacted. Of the remaining 206 participants, 4 were excluded from the analyses ( 2 incomplete questionnaires and 2 women underwent radiotherapy or chemotherapy). Thus, complete data from 202 patients were included in this study. These participants were not currently receiving any cancer therapy other than hormone therapy. After medical appointments, the participants were interviewed to assess socio-demographic variables. Data on clinical variables were obtained from medical records.

A comparison group was also recruited. For breast cancer survivor, one woman with no cancer history matched with regard to age (plus or minus two years) was chosen for the comparison group. Convenience sampling was 
used. The comparison group consisted of women receiving treatment at the primary healthcare unit located in the downtown area in the same city as the two research hospitals. In addition to age matching, these women also should be 18 years or older, with no previous or present history of cancer, and preserve cognitive function and communication. All 202 controls were interviewed in a healthcare unit to assess socio-demographic and clinical variables as well as fatigue and quality of life.

Data were collected between December 2008 and June 2010 by one of the investigators. The Ethics Committee of all participating institutions agreed with the study, and all subjects provided written Informed Consent for study participation.

\section{Measures}

The Piper Fatigue Scale-Revised (R-PFS) is a subjective fatigue assessment instrument that covers 4 subscales: behavioral/severity (6 items), affective meaning (5 items), sensory (5 items), and cognitive/mood (6 items). The psychometric properties have been validated in a sectional study in female survivors of breast cancer ${ }^{32}$. The Brazilian version of the R-PFS contains 22 items that loaded well (factor loading $>0.35$ ) on 3 dimensions identified by factor analysis (behavioral, affective and sensory/psychological) and provides an overall total fatigue score. Items are listed in a numerical scale, and each item is measured on a scale of 0 to 10 . The Brazilian version of the R-PFS has been validated, and psychometric properties were considered satisfactory for oncological use in Brazilian populations ${ }^{33}$.

The abbreviated version of the World Health Organization Quality of Life Instrument (WHOQOL-BREF) is a generic quality of life instrument developed by the World Health Organization. The measure contains 4 domains: physical ( 7 items), psychological (6 items), social relationships (3 items) and environment (8 items). Higher scores indicate a better quality of life ${ }^{34}$. The WHOQOL-BREF has been translated and validated in Brazilian Portuguese and its psychometric properties were considered satisfactory ${ }^{35}$.

\section{Statistical analysis}

Data were presented as mean, standard deviation, median, minimum and maximum values or absolute and relative frequencies according to the variable type. The Piper total fatigue and subscale scores were analyzed as a continuous variable. The scores were obtained by summing the total items or the individual items of each subscale and dividing by the total number of items or the number of items in the subscale, respectively. Higher scores indicate greater fatigue.

Scoring procedures for the WHOQOL-BREF items were used according to the WHOQOL scoring manual ${ }^{36}$.
Scores were transformed into a 0 to 100 scale. A higher score represented a better quality of life.

The $\chi^{2}$ test was used to compare socio-demographic variables and the number of comorbidities between breast cancer survivors and women with no cancer history.

The generalized linear model was used to compare total and subscale fatigue scores and quality of life scores between breast cancer survivors and women with no cancer history. Controls for potentially confounding variables (i.e. educational level, marital status, and number of comorbidities) were also considered.

The relationship of total and subscale fatigue scores with quality of life scores among breast cancer survivors were examined by calculating the Spearman correlation coefficient. For comparison purposes, the relationship of total and subscale fatigue scores with quality of life scores were also examined among women with no cancer history.

Statistical analysis was performed with Statistical Package for the Social Sciences (SPSS) version 17.0 (SPSS Inc., Chicago, United States). Two-tailed p-values $<0.05$ were considered statistically significant.

\section{Results}

Characteristics of breast cancer survivors and the comparison group

The breast cancer survivors diagnosed with in situ to Stage III breast cancer in this study ranged in age from 31 to 85 years old (mean age: 54.5 years old; standard deviation - $\mathrm{SD}=10.4)$, and the average length of time since diagnosis was 5.2 years $(\mathrm{SD}=4.6)$. The comparison group ranged in age from 32 to 86 years old (mean age: 55.3 years old; $\mathrm{SD}=11.1$ ). Additional socio-demographic variables are presented and compared in Table 1. Comparisons between the two groups displayed significant differences for educational level $(\mathrm{p}=0.003)$, which was greater in the comparison group, and the percentage of partnered women, which was increased in breast cancer survivors compared with the women with no cancer history $(\mathrm{p}<0.001)$. Moreover, women with no cancer history displayed an increased number of comorbidities compared with survivors $(\mathrm{p}<0.001)$.

Approximately $76 \%$ of the survivors were post-menopausal, and $46 \%$ were diagnosed with stage II breast cancer. In addition, $89.1 \%$ of the survivors received radiation therapy and/or chemotherapy, and $55 \%$ were taking hormone therapy. Approximately $51 \%$ of survivors displayed at least 1 comorbidity. The most common comorbidities for survivors were as follows: hypertension $(27.7 \%)$, musculoskeletal disease (14.9\%), and depression (13.4\%). Many women in the comparison group (79.2\%) displayed at least 1 comorbidity. The most common 
comorbidities for the comparison group were as follows: hypertension (48\%), musculoskeletal disease (20.7\%), and dyslipidemia (19.3\%).

\section{Fatigue and quality of life}

The continuous Piper total fatigue scores ranged from 0 to 9.59 among breast cancer survivors and from 0 to 9.39 among women with no cancer history; a higher score indicates more severe symptoms. The total average scores were $2.8(\mathrm{SD}=2.9)$ and $1.1(\mathrm{SD}=2.4)$ for survivors and women with no cancer history, respectively. Table 2 displays the total and subscale fatigue scores for the two groups. Significant differences between the two groups for the reported total and all subscales fatigue scores were observed; breast cancer survivors displayed

Table 1. Description of the breast cancer survivors group and women with no cancer history group according to socio-demographic variables and number of comorbidities

\begin{tabular}{|c|c|c|c|}
\hline \multirow[t]{2}{*}{ Variables } & $\begin{array}{l}\text { Breast cancer } \\
\text { survivors } \\
(n=202)\end{array}$ & $\begin{array}{c}\text { Women with no } \\
\text { cancer history } \\
(n=202)\end{array}$ & \multirow[t]{2}{*}{ p-value } \\
\hline & $n(\%)$ & n (\%) & \\
\hline Age at inferview (years) & & & 1 \\
\hline$\leq 50$ & $73(36.1)$ & $73(36.1)$ & \\
\hline$>50$ & $129(63.9)$ & $129(63.9)$ & \\
\hline Ethnicity & & & 0.5 \\
\hline White & $160(79.2)$ & $165(81.7)$ & \\
\hline Non-white & $42(20.8)$ & $37(18.3)$ & \\
\hline Educational level(years) & & & 0.003 \\
\hline Elementary school & $131(64.9)$ & $103(51.5)$ & \\
\hline Middle school & $54(26.7)$ & $65(32.5)$ & \\
\hline High school & $17(8.4)$ & $32(16.0)$ & \\
\hline Marital status & & & $<0.001$ \\
\hline With partner & 134 (66.3) & $82(40.6)$ & \\
\hline Without partner & $68(33.7)$ & $120(59.4)$ & \\
\hline Children & & & 0.2 \\
\hline 0 & $19(9.4)$ & $29(14.4)$ & \\
\hline $1-2$ & $95(47.0)$ & $90(44.8)$ & \\
\hline$\geq 3$ & $88(43.6)$ & $82(40.8)$ & \\
\hline Employment status & & & 0.4 \\
\hline Employed & $84(41.6)$ & $90(45.5)$ & \\
\hline Unemployed & 118 (58.4) & $108(54.5)$ & \\
\hline $\begin{array}{l}\text { Individual income per } \\
\text { month* }\end{array}$ & & & 0.2 \\
\hline$\leq 1$ & $134(67.3)$ & $107(60.5)$ & \\
\hline$>1$ & $65(32.7)$ & $70(39.5)$ & \\
\hline Number of comorbidities & & & $<0.001$ \\
\hline None & $98(48.5)$ & $42(20.8)$ & \\
\hline 1 & $51(25.2)$ & $65(32.2)$ & \\
\hline 2 & $27(13.4)$ & $44(21.8)$ & \\
\hline$\geq 3$ & $26(12.9)$ & $51(25.2)$ & \\
\hline
\end{tabular}

All tests were performed using $\chi^{2}$ analysis.

*Expressed as one minimum wage (Brazil) = approximately US $\$ 287.3$ on 26

November, 2014.

Note: the total numbers vary due to missing information on some variable. higher scores than women with no cancer history (all p-values $<0.05$ ).

WHOQOL-BREF scores for the breast cancer survivors and women with no cancer history are displayed in Table 3. The highest quality of life scores for breast cancer survivors were reported in the social relationships domain followed by the environmental domain. The lowest quality of life score was found in the physical domain. Comparing the WHOQOL-BREF scores between groups, breast cancer survivors reported significantly lower scores in the physical $(\mathrm{p}=0.002)$, psychological $(\mathrm{p}=0.03)$, and social relationships $(\mathrm{p}=0.03)$ domains than women with no cancer history. No significant difference in environmental domain scores $(\mathrm{p}=0.08)$ was observed between the two groups.

In addition to evaluate the level of fatigue and quality of life experienced by breast cancer survivors and the comparison group, we were interested in examining the correlation between fatigue and quality

Table 2. Description of mean scores, median and range of fatigue (Piper Fatigue Scale-Revised) in breast cancer survivors and women with no cancer history

\begin{tabular}{|c|c|c|c|c|c|}
\hline & \multicolumn{2}{|c|}{$\begin{array}{l}\text { Breast cancer survivors } \\
\qquad(\mathrm{n}=202)\end{array}$} & \multicolumn{2}{|c|}{$\begin{array}{c}\text { Women with no cancer } \\
\text { hisfory } \\
(n=200)^{*}\end{array}$} & \multirow{2}{*}{ p-value** } \\
\hline & Mean (SD) & $\begin{array}{l}\text { Median } \\
\text { (range: } \\
0-10) \\
\end{array}$ & $\begin{array}{l}\text { Mean } \\
\text { (SD) }\end{array}$ & $\begin{array}{l}\text { Median } \\
\text { (range: } \\
0-10 \text { ) }\end{array}$ & \\
\hline Total fatigue & $2.8(2.9)$ & $2.3(0-9.6)$ & $1.1(2.4)$ & $0(0-9.4)$ & 0.04 \\
\hline Behavioral & $2.6(3)$ & $1.3(0-10)$ & $0.9(2.2)$ & $0(0-10)$ & $<0.001$ \\
\hline Affective & $3.2(3.6)$ & $1.4(0-10)$ & $1.6(3.3)$ & $0(0-10)$ & 0.005 \\
\hline $\begin{array}{l}\text { Sensory/ } \\
\text { cognitive }\end{array}$ & $2.7(2.8)$ & $2.1(0-9.6)$ & $1(2.3)$ & $0(0-9.9)$ & 0.01 \\
\hline
\end{tabular}

Table 3. Description of mean scores, median and range of quality of life (World Health Organization Quality of Life Instrument) in breast cancer survivors and women with no cancer history

\begin{tabular}{|c|c|c|c|c|c|}
\hline \multirow{2}{*}{ Domains } & \multicolumn{2}{|c|}{$\begin{array}{c}\text { Breast cancer } \\
\text { survivors } \\
\text { (n=202) }\end{array}$} & \multicolumn{2}{|c|}{$\begin{array}{c}\text { Women with } \\
\text { no cancer history } \\
(\mathrm{n}=200)^{*}\end{array}$} & \multirow{2}{*}{ p-value** } \\
\hline & $\begin{array}{l}\text { Mean } \\
\text { (SD) }\end{array}$ & $\begin{array}{l}\text { Median } \\
\text { (range: } \\
0-100 \text { ) }\end{array}$ & $\begin{array}{l}\text { Mean } \\
\text { (SD) }\end{array}$ & $\begin{array}{l}\text { Median } \\
\text { (range: } \\
0-100 \text { ) }\end{array}$ & \\
\hline Physical & $63.1(17.8)$ & $63.4(0-100)$ & $67.7(20.8)$ & $74.9(7.1-99.8)$ & 0.002 \\
\hline Psychological & $66.2(18.4)$ & $70.8(0-100)$ & $70(22.6)$ & $75(8.3-100)$ & 0.03 \\
\hline $\begin{array}{l}\text { Social } \\
\text { relationships }\end{array}$ & $74.2(20.1)$ & $75(0-100)$ & $76(23.2)$ & $83.3(0-100)$ & 0.03 \\
\hline Environmental & $64.3(16.6)$ & $68.7(0-100)$ & $68.3(17.7)$ & $68.8(18.8-100)$ & 0.08 \\
\hline
\end{tabular}


of life. The relationship between fatigue and quality of life scores was similar among the breast cancer survivors and women with no cancer history. In both groups, higher total and subscale fatigue scores were significantly associated with poorer quality of life for all domains (all p-values $<0.01$ ).

The physical domain of quality of life for breast cancer survivors was most strongly correlated with total fatigue score $(\mathrm{r}=-0.6)$ and subscale fatigue $(\mathrm{r}=-0.6$ for behavior, $r=-0.53$ for affective and $r=-0.58$ for sensory/cognitive subscale). The lowest correlation was found for social relationship domain of quality of life and sensory/cognitive fatigue subscale $(r=-0.28)$. The physical domain of quality of life for women with no cancer history was also more strongly correlated with total fatigue score $(\mathrm{r}=-0.39)$ and subscale fatigue $(r=-0.39$ for behavior, $r=-0.37$ for affective and $r=-0.4$ for sensory/cognitive subscale). The lowest correlation was found for social relationship domain of quality of life and sensory/cognitive fatigue subscale $(r=-0.26)$.

\section{Discussion}

In the current study, fatigue and quality of life in breast cancer survivors were compared with women of a similar age with no cancer history. In addition, correlations among fatigue and quality of life were assessed in both groups.

Breast cancer survivors and women with no cancer history differed in their total fatigue and subscale scores, with higher levels of fatigue evident in survivors. These findings diverge somewhat from other reports in the literature indicating no differences in fatigue for survivors of breast cancer compared with controls ${ }^{23,24}$.

Bower et al. ${ }^{11}$ assessed fatigue and quality of life in disease-free breast cancer survivors $(n=1,957)$ at stage 0 , I, or II of diagnosis between 1 and 5 years after initial breast cancer diagnosis using the Medical Outcomes Study (SF-36). The breast cancer survivors reported slightly lower levels of fatigue than age-matched women from the general population. In addition, the study showed that survivors reported increased levels of fatigue compared with similar demographic and socio-economic group of women at high risk for breast cancer.

Evidence suggests that fatigue appears to be increased in breast cancer survivors compared with control group $9,10,15,20-22$. For example, Andrykowski et al. ${ }^{9}$ evaluated 88 breast cancer survivors with stage 0-IIIa breast cancer (an average of 28 months after treatment) and observed greater fatigue (Piper Fatigue Scale and the Medical Outcomes Study Vitality Scale) than an age-matched sample of 88 women with benign breast problems and no history of breast cancer at an initial and 4-month assessment. In a more recent study, Lee et al. ${ }^{15}$ reported that stage I-IV breast cancer survivors referred increased fatigue (The European Organisation for Research and Treatment of Cancer - EORTC QLQ-C30) soon after diagnosis $(n=286)$ and 1 year later $(n=206)$ compared with general female population. These findings are consistent with the findings of this study, reinforcing the observation that survivors may experience more severe fatigue than women with no cancer history matched for age and adjusted for other confounding variables. It would be important to raise the awareness of professionals regarding the fatigue of breast cancer survivors, thereby exposing the diagnosis and treatment advances and encouraging additional investment by health managers in specific training for counseling, fatigue assessment tools, quantitative measurements and appropriate therapeutic approaches.

In a study about fatigue, associations of fatigue with health variables were identified in the general population. Subjects who reported illnesses or health problems displayed higher scores for total, mental, and physical fatigue when adjusted for the age and sex of the individuals who reported no health problems ${ }^{18}$. In the light of the fatigue level results in this current study, it is interesting to note that increased fatigue was reported for the survivors despite the fact that the majority of women with no cancer history reported a significantly increased number of comorbidities compared with survivors. These findings suggest that fatigue status is related at least partially with cancer disease. More in-depth research on the relationship between current health problems and comorbidities in patients and cancer survivors is warranted.

With regard to quality of life, breast cancer survivors and women with no cancer history showed different results for the quality of life domains. Breast cancer survivors reported significantly lower scores than women with no cancer history for physical, psychological and social relationships domains. On the other hand, environmental domains were similar between breast cancer survivors and women with no cancer history.

In a study by Amir and Ramati ${ }^{25}$, long-time breast cancer survivors displayed significantly lower scores for the physical and psychological domains (WHOQOL-BREF) compared with women not reporting any chronic disease. The physical impairment of the breast cancer survivors was observed in previous studies ${ }^{24,28}$. Romito et al. ${ }^{37}$, in a study involving 255 Italian long-term breast cancer survivors, suggested that health-related quality of life (The Medical Outcomes Study Short Form 12), especially the physical aspect, was worse than in healthy subjects even a decade after the cancer experience. This result was particularly true for younger breast cancer survivors. 
The psychological aspect of quality of life was also worse, because the depressive symptoms (The Zung Self-rating Depression Scale) were observed in about $30 \%$ of the cases and fatigue (The Brief Fatigue Inventory) showed a similar pattern.

Effective treatment for breast cancer can produce a good ten-year survival rate compared with other cancer types. However, the potential psychological dysfunction caused by sexual and physical diagnosis and treatment can have a deleterious effect on the quality of life in women. The treatment options may have similar results in terms of response and survival but can variably affect emotional $^{38}$ and physical well-being ${ }^{21,27,38}$. Therefore, physical activity and psychosocial interventions are recommended for practice?

The survivors reported poorer ratings for the social relationships domain compared with the control group. This finding may indicate that friends, relatives or caregivers did not provide targeted assistance to breast cancer survivors in this area. Family and friends should be counseled about the importance of social support for survivors who require special attention even after the initial phase of diagnosis and treatment. As an example, a project of psychosocial intervention provided positive short- and long-term results for patients after breast cancer treatment; improved quality of life and reduced health care costs were observed in patients receiving intervention compared with women with no psychosocial intervention ${ }^{39}$.

The environmental domain did not differ between the two groups, which may have resulted from similarities in socio-demographic characteristics between the groups, such as age at interview, ethnicity, children, employment status, and individual income per month.

The survivors and women with no cancer history reported a similar impact of fatigue on quality of life. In both groups, higher total and subscale fatigue scores were significantly correlated with poorer quality of life. In accordance with these findings, it appears that the impact of fatigue on quality of life does not differ for survivors and women with no cancer history. These findings are also consistent with research reporting that fatigue severity correlates with poorer quality of life in breast cancer survivors ${ }^{7,11,12,16,23,37}$ and in healthy women ${ }^{23}$.

Schmidt et al. ${ }^{16}$ investigated different courses of fatigue (Fatigue Assessment Questionnaire) and quality of life (EORTC QLQ-C30) at follow-up (median: 5.8 years) and retrospectively rated fatigue level pre-diagnosis, during different treatment phases, and 1 year post-surgery in 1,928 disease-free breast cancer survivors and comparisons with the general population. Survivors with persisting long-term fatigue had worse scores for all quality of life functions and symptoms about six years post-diagnosis than other survivors and compared to the general population.

Cancer-related fatigue affects functioning and impacts quality of life. Possible causal factors include physical conditions, affective and cognitive states, pro-inflammatory cytokines, and metabolic factors ${ }^{7}$. In the present study, higher fatigue scores for survivors were most strongly related to the physical domain of quality of life, reinforcing the findings that physical symptoms (such as pain, dyspnea, insomnia, and nausea and vomiting) serve as predictors of fatigue in breast cancer survivors ${ }^{30}$.

Fatigue should be screened and monitored closely by healthcare professionals, and patients should understand that fatigue can impair health and quality of life. Furthermore, the barriers that may interfere with approach of fatigue (i.e. patients believe that the doctors would discuss fatigue if it was a major issue and lack of fatigue documentation and supportive care referrals) reflect the need to develop and implement educational strategies for patients and providers for better communication and treatment of fatigue ${ }^{40}$.

During the continuous treatment of women with breast cancer, clinicians must screen, further assess as indicated, and treat cancer-related fatigue, because it is associated with emotional distress and limits function and willingness to exercise ${ }^{7}$. Moreover, persistent fatigue post-treatment may lead to extensive long-term loss in quality of life, concerning physical, social, cognitive, and financial aspects. Therefore, fatigue management should be obligatory during and after cancer treatment ${ }^{16}$.

Although quality of life is a decisive and important outcome measure for cancer patients and treatment ${ }^{41}$, targeted interventions to alleviate fatigue may improve the quality of life for both survivors and women without cancer.

Limitations were related to study design (cross-sectional). In addition, no causal relations among the variables and fatigue and quality of life could be established, and these relationships did not change over time. The study was conducted at two medical centers, and the findings cannot be generalized. Despite these limitations, the current study was designed including two standard, multidimensional, internationally validated measures: the R-PFS and the WHOQOL-BREF. Additionally, this study included an age- and gender-matched comparison group composed of women with no history of cancer.

The findings of this study provide directions for assessment, monitoring, and treatment programs to prevent or reduce fatigue in breast cancer patients upon completion of treatment and highlight the importance of assessing the quality of life in this population. 
1. Parkin DM, Bray F, Ferlay J, Pisani P. Global cancer statistics, 2002. CA Cancer J Clin. 2005;55(2):74-108.

2. Cancer Research UK [Internet]. Breast cancer [cited 2014 Nov 24]. Available from: <http://publications.cancerresearchuk.org/ downloads/Product/CS_KF_BREAST.pdf>

3. Brasil. Ministério da Saúde. Instituto Nacional de Câncer José Alencar Gomes da Silva [Internet]. Estimativa 2014: incidência de câncer no Brasil. Rio de Janeiro: INCA; 2014 [citado 2014 Nov 25]. Disponível em: <http://www.inca.gov.br/estimativa/2014/ estimativa-24042014.pdf>

4. DeSantis CE, Lin CC, Mariotto AB, Siegel RL, Stein KD, Kramer $\mathrm{JL}$, et al. Cancer treatment and survivorship statistics, 2014. CA Cancer J Clin. 2014;64(4):252-71.

5. Centers for Disease Control and Prevention [Internet]. Basic information about cancer survivorship, 2014 [cited 2014 Nov 25]. Available from: <http://www.cdc.gov/cancer/survivorship/ basic_info/>

6. Wang XS, Zhao F, Fisch M, O'Mara AM, Cella D, Mendoza TR, et al. Prevalence and characteristics of moderate to severe fatigue: a multicenter study in cancer patients and survivors. Cancer. 2014; 120(3):425-32.

7. Berger AM, Gerber LH, Mayer DK. Cancer-related fatigue: implications for breast cancer survivors. Cancer. 2012;118/8 Suppl):2261-9.

8. Portenoy RK, Itri LM. Cancer-related fatigue: guidelines for evaluation and management. Oncologist. 1999;4(1):1-10.

9. Andrykowski MA, Curran SL, Lightner R. Off-treatment fatigue in breast cancer survivors: a controlled comparison. J Behav Med. 1998;21(1):1-18.

10. Broeckel JA, Jacobsen PB, Horton J, Balducci L, Lyman GH. Characteristics and correlates of fatigue after adjuvant chemotherapy for breast cancer. J Clin Oncol. 1998;16(5):1689-96.

11. Bower JE, Ganz PA, Desmond KA, Rowland JH, Meyerowitz BE, Belin RR. Fatigue in breast cancer survivors: occurrence, correlates and impact on quality of life. J Clin Oncol. 2000; 18(4):743-53.

12. Meeske K, Smith AW, Alfano CM, McGregor BA, McTiernan A, Baumgartner $K B$, et al. Fatigue in breast cancer survivors two to five years post diagnosis: a HEAL Study report. Qual Life Res. 2007; 16(6):947-60.

13. Kim SH, Son BH, Hwang SY, Han W, Yang J, Lee S, et al. Fatigue and depression in disease-free breast cancer survivors: prevalence, correlates, and association with quality of life. J Pain Symptom Manage. 2008;35(6):644-55.

14. Alexander S, Minton O, Andrews P, Stone P. Comparison of the characteristics of disease-free breast cancer survivors with or without cancer-related fatigue syndrome. Eur J Cancer. 2009;45(3):384-92.

15. Lee ES, Lee MK, Kim SH, Ro JS, Kang HS, Kim SW, et al. Health-related quality of life in survivors with breast cancer 1 year after diagnosis compared with general population: a prospective cohort study. Ann Surg. $2011 ; 253(1): 101-8$.

16. Schmidt ME, Chang-Claude J, Vrieling A, Heinz J, Flesch-Janys $D$, Steindorf K. Fatigue and quality of life in breast cancer survivors: temporal courses and long-term pattern. J Cancer Surviv. 2012;6(1):11-9.

17. Cella D, Lai JS, Chang CH, Peterman A, Slavin M. Fatigue in cancer patients compared with fatigue in the general United States population. Cancer. 2002;94(2):528-38.
18. Loge $\mathrm{JH}$, Ekeberg $\mathrm{O}$, Kaasa $\mathrm{S}$. Fatigue in the general Norwegian population: normative data and associations. J Psychom Res. 1998;45(1):53-65.

19. Jacobsen PB, Donovan KA, Small BJ, Jim HS, Munster PN, Andrykowski MA. Fatigue after treatment for early stage breast cancer: a controlled comparison. Cancer. 2007; 1 10(8):1851-59.

20. Ahn SH, Park BW, Noh DY, Nam SJ, Lee ES, Lee MK, et al. Health-related quality of life in disease-free survivors of breast cancer with the general population. Ann Oncol. 2007;18(1):173-82.

21. Robb C, Haley WE, Balducci L, Extermann M, Perkins EA, Small $B J$, et al. Impact of breast cancer survivorship on quality of life in older women. Crit Rev Oncol Hematol. 2007;62(1):84-91.

22. Von Ah DM, Russell KM, Carpenter J, Monahan PO, Qianqian Z, Tallman E, et al. Health-related quality of life of African American breast cancer survivors compared with healthy African American women. Cancer Nurs. 2012;35(5):337-46.

23. Hann DH, Jacobsen P, Martin S, Azzarello L, Greenberg H. Fatigue and quality of life following radiotherapy for breast cancer: a comparative study. J Clin Psychol Med Settings. 1998;5(1): 19-33.

24. Tomich PL, Helgeson VS. Five years later: a cross-sectional comparison of breast cancer survivors with healthy women. Psychooncology. 2002; 11 (2): 154-69.

25. Amir M, Ramati A. Post-traumatic symptoms, emotional distress and quality of life in long-term survivors of breast cancer: a preliminary research. J Anxiety Disord. 2002; 16(2): 195-206.

26. Ganz PA, Rowland JH, Desmond K, Meyerowitz BE, Wyatt GE. Life after breast cancer: understanding women's health-related quality of life and sexual functioning. J Clin Oncol. 1998;16(2):501-14.

27. Trentham-Dietz A, Sprague BL, Klein R, Klein BE, Cruickshanks KJ, Fryback DG, et al. Health-related quality of life before and after a breast cancer diagnosis. Breast Cancer Res Treat. 2008; 109(2):379-87.

28. Helgeson VS, Tomich PL. Surviving cancer: a comparison of 5-year disease free breast cancer survivors with healthy women. Psychooncology. 2005; 14(4):307-17.

29. Harrison SE, Watson EK, Ward AM, Khan NF, Turner D, Adams $E$, et al. Primary health and supportive care needs of long-ferm cancer survivors: a questionnaire survey. J Clin Oncol. $2011 ; 29(15): 2091-8$.

30. Kluthcovsky AC, Urbanetz AA, Carvalho DS, Maluf EM, Sylvestre GC, Hatschbach SB. Fatigue after treatment in breast cancer survivors: prevalence, determinants and impact on health-related quality of life. Support Care Cancer. 2012;20(8):1901-9.

31. Kluthcovsky AC, Urbanetz AA. [Quality of file in breast cancer survivors compared to healthy women]. Rev Bras Ginecol Obstet. 2012;34(10):453-8. Portuguese.

32. Piper BF, Dibble SL, Dodd M, Weiss MC, Slaughter RE, Paul SM. The revised Piper Fatigue Scale: psychometric evaluation in women with breast cancer. Oncol Nurs Forum. 1998;25(4):677-84.

33. Mota DD, Pimenta CA, Piper BF. Fatigue in Brazilian cancer patients, caregivers, and nursing students: a psychometric validation study of the Piper Fatigue Scale-Revised. Support Care Cancer. $2009 ; 17(6): 645-52$

34. Skevington SM, Lotfy M, O'Connell KA; WHOQOL Group. The World Health Organization's WHOQOL-BREF quality of life assessment: psychometric properties and results of the international field trial. A report from the WHOQOL group. Qual Life Res. 2004;13(2):299-310. 
35. Fleck MP, Louzada S, Xavier M, Chachamovich E, Vieira G, Santos $L$, et al. Aplicação da versão em português do instrumento abreviado de avaliação de qualidade de vida WHOQOL-BREF. Rev Saude Publica. 2000;34(2):178-83.

36. World Health Organization [Internet]. Program on mental health: WHOQOL user manual [cited 2014 Nov 24]. Geneva: WHO; 1998. Available from: <http://www.who.int/mental_health/ evidence/who_qol_user_manual_98.pdf>

37. Romito F, Cormio C, Giotta F, Colucci G, Mattioli V. Quality of life, fatigue and depression in Italian long-term breast cancer survivors. Support Care Cancer. 2012;20(1 1):2941-8.
38. Fallowfield L. Assessment of quality of life in breast cancer. Acta Oncol. 1995;34(5):689-94.

39. Simpson JS, Carlson LE, Trew ME. Effect of group therapy for breast cancer on healthcare utilization. Cancer Pract. 2001;9(1):19-26.

40. Borneman T, Piper BF, Sun VC, Koczywas M, Uman G, Ferrell $B$. Implementing the fatigue guidelines at one NCCN member institution: process and outcomes. J Natl Compr Canc Netw. 2007; 5(10): 1092-101.

41. Arndt V, Merx H, Stürmer T, Stegmaier C, Ziegler H, Brenner H. Age specific detriments to quality of life among breast cancer patients one year after diagnosis. Eur J Cancer. 2004;40(5):673-80. 